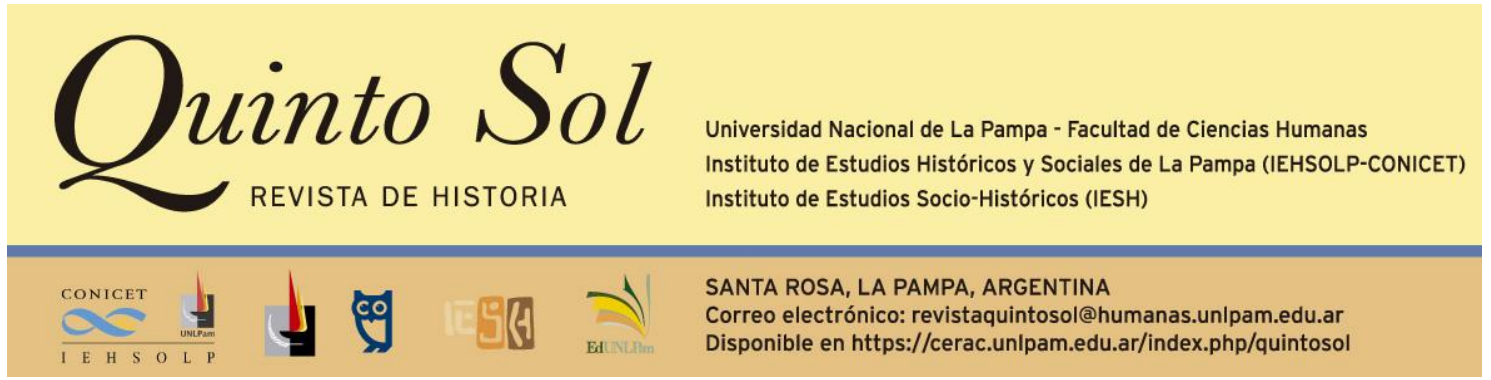

Quinto Sol, vol. 23, n², mayo-agosto, ISSN 1851-2879, pp. 1-4

DOI: http://dx.doi.org/10.19137/qs.v23i2.3741

Esta obra se publica bajo licencia Creative Commons 4.0 Internacional. (Atribución-No ComercialCompartir Igual)

\title{
Mabel Fernández (Comp.) Género, saberes y labores de las sociedades indígenas pampeano-patagónicas. Buenos Aires: Editorial Universidad Nacional de Luján, 2018, 386 páginas.
}

\author{
Alicia Ana Fernández Distel \\ Fundación Cultural y Educativa "Nicasio Fernández Mar". Tilcara, Jujuy. \\ Argentina \\ Correo electrónico: aliciana04@hotmail.com
}

Dos prólogos se enfrenta el lector al iniciar este libro. El primero, escueto, explica el ¿porqué mujer?, o sea porqué este libro alude a campos de acción femeninos. Es responsabilidad de Cecilia Lagunas, coordinadora del área mujer en la Universidad Nacional de Luján. El segundo, más explicativo, lleva el título de "Porqué géneros, saberes y labores..." y del mismo se responsabilizan los doctores Mariano Ramos y Mabel Fernández, docentes-investigadores de la misma universidad, aunque reunir las contribuciones, hacerlas evaluar y darles forma de libro le compitió a la segunda. Una entrega muy esforzada ya que no escatima complementos explicativos e ilustrativos, como serían los mapas, las tablas, las ilustraciones en blanco y negro y en color.

En la introducción, Ramos y Fernández, quienes participan del Programa de Arqueología Histórica y Estudios Pluridisciplinarios, deslizan la idea que el tema de los saberes y la división sexual del trabajo en épocas cazadoras-recolectoras es un tanto utópico y por demás ambicioso. Más factible es abordar el asunto de las mujeres indias 
en tiempos del contacto con el europeo. De hecho, el libro dedica buena parte de los textos al tema etnohistórico y al pueblo mapuche que participa de las características de las etnias tardías, desarrolladas, del área andina. Sin embargo, los dos primeros capítulos se retrotraen a los inicios de la era cristiana y tal vez más atrás en el tiempo.

El primer trabajo, de Marcelo Vitores, comienza con "Supuestos de género en la cerámica patagónica". Este acápite tiene en cuenta una cantidad de investigaciones de cuevas, las que como dice Vítores, le dan "indicios materiales" de todo cuanto se pueda inferir a partir de la literatura de viajeros. Como sucede en sociedades primitivas de la ecúmene, la alfarería fue cosa de mujeres con mucha complementación de los esposos o hijos en detalles relacionados con trabajos pesados. Pensando que el investigador ubica en el 1800 AP la entrada de la alfarería en Patagonia, estamos sí, en el marco de sociedades nómades con fuerte sustrato cazador-recolector.

El capítulo siguiente, a cargo de María Teresa Boschín, es un meduloso trabajo en torno a la producción de arte rupestre en el área propuesta. Antecedido por reflexiones teórico-metodológicas comparativas sobre el hecho del "descubrimiento" del arte parietal y la fe de autenticidad. Ello entre Europa y América. En nuestro continente nunca hubo que discutir sobre la autoría del arte rupestre, en cambio en el Viejo Mundo sí, ya que allí había desaparecido el nexo, que en nuestras latitudes lo da el aborigen. También la autora explica que no es lo mismo encontrar un repertorio femenino de temas en los dibujos (uno por ejemplo sería el de la vulva), que atestiguar la manufactura femenina de los diseños parietales. Lo segundo estaría por demás explicado ya que compete a la mujer indígena el manipular tintes y colorantes, sean para los tejidos, los cueros o las piedras... Tal vez con los grabados la situación podría variar: horadar la piedra es una tarea más violenta, hipotéticamente masculina.

La compiladora de este libro, la propia Mabel Fernández, también hace una contribución amplia, buscando otras facetas al asunto. Como por ejemplo el desconfiar de una información documental (una fuente de siglos pasados) porque el cronistadescubridor-viajero, siempre estará involucrado con un modelo de mujer: el reinante en Europa. Por ello la tabulación que proviene del viajero George Musters (1871), por ejemplo, sobre cuáles son las tareas femeninas y cuáles las masculinas en el ámbito patagónico no son tan de tener en cuenta: hay distorsiones. La introducción de testimonios directos, grabaciones de charlas de primera mano con las indias, traen mucha luz al tema. La segunda mitad del siglo XX y los comienzos del XXI (trabajo de Azar en este libro), brinda recopilaciones vívidas y fundamentadas.

Luego sigue el aporte de dos grandes trabajadoras en el campo de la arqueología histórica: Alicia Tapia y Lía Pera, quienes se dedican a la sociedad ranquelina del siglo XIX. Su aproximación al tema es desde lo social. El grueso de la información atañe al entorno del cacique (jefe) y a sus mujeres de linaje. Estas últimas están compenetradas de todos los saberes de trasmisión generacional, contando la fabricación de artesanías y la horticultura. Hasta las cautivas cuentan en esta seguidilla de trasmisiones. Se cotejan los datos de las fuentes históricas con los resultados de las excavaciones propias y de las colecciones existentes en museos.

La antropóloga Gloria Arrigoni aborda en el capítulo $\mathrm{V}$ a la sociedad tehuelche, nombre étnico que les fue impuesto por sus complementarios tribales: los mapuche. Analiza el nefasto estereotipo de género que en trabajos poco razonados lleva a especificar sin fundamentos roles que terminan siendo meras elaboraciones académicas. Como surge del testimonio de la india Pati (Aguerre, 2000), una mujer 
podía hacer cosas bien "masculinas", como fabricar un raspador. Arrigoni recalca que solo una aproximación fenomenológica al testimonio del informante permitirá dejar de lado la infiltración de preconceptos occidentales. En este marco, lo primero que surge es anotar que el rol de chaman (en mapuche "machi") lo desempeñaba indiferentemente un hombre o una mujer. Y sugiere que quizás lo que se ve en pinturas y grabados fue realizado en un estado alterado de conciencia; posiblemente el arte (con la consecuente preparación de pócimas y mezclas colorantes) era parte de ritos de iniciación chamánica. Chamanismo lo tuvieron los dos pueblos bajo análisis: tehuelche y mapuche.

El sexto capítulo está a cargo de Pablo F. Azar, quien trae al libro la frescura del testimonio directo, del trabajo de campo reciente (2006) con una informante mapuche. Lo hace de acuerdo a las Guías ya institucionalizadas en Antropología; su seguidilla de preguntas alude al ciclo vital de la mujer. Introduce como novedad relacionar los hallazgos arqueológicos en una cueva neuquina con los decires de su colaboradora, aludiendo a la cultura material. Maneja fuentes interesantes (como Hilger, Schindler, Erize), aunque emanadas del pueblo mapuche chileno.

El último capítulo proyecta al lector a cómo trasmitir los saberes sobre el indigenado de ayer en la escuela argentina actual. Lo escriben dos investigadoras de la Universidad Nacional de La Pampa: Stella Cornelis y Mirta Zink. Con un acendrado afán pedagógico, primero analizan, paso a paso, el contenido del tomo que se presenta aquí. Luego generan un resumen sobre los roles masculinos y femeninos detectados en las sociedades del pasado, versión que es apta para figurar en textos escolares. Esta síntesis incorpora la interesante expresión de "en determinadas circunstancias ciertas tareas pueden haberlas realizado indistintamente cualquiera de ellos (hombres o mujeres indias)". Es decir que se da un viso de realidad a lo que evidentemente no fue tan tajante. Terminan proponiendo tareas de aula bien concretas, que no solo introducen al alumno en el tema de los antiguos patagónicos, sino que también revalorizan el trabajo del arqueólogo, antropólogo e historiador. Tal vez, porqué no, dando nacimiento a futuras vocaciones.

Respecto a los roles de la niñez las autoras revalorizan trabajos de "etnoarqueología", una rama de la prehistoria que busca en pueblos del presente razones de conductas del pasado. Los resultados de Gustavo Politis $(1998,1999)$ al respecto se enfatizan, entre otros, porque muestran que el niño indio tiene muchos roles y que no merece ser invisibilizado. Mis propios trabajos en torno al arte rupestre de Jujuy han demostrado que hay figuras que se asocian al monigote, esa figura humana tan idealizada, que el niño de toda raza o época elige según la psicología evolutiva (Fernández Distel, 2008). Niños confeccionando arte rupestre (jen el caso de Jujuy, grabado!), entonces, también los hubo en Patagonia.

Cada capítulo finaliza con una nutrida bibliografía que sirve como desencadenante de más investigaciones. Una fuente que no encontré citada en ningún apartado del libro que estoy comentando es El concepto de pillán entre los Mapuche de Ewald Böning (1995), traducción del alemán en la que estuve involucrada. Como en el caso de María Inez Hilger (1957), este es un sustancioso tratado sobre la religión de los mapuche, aunque con el afán histórico cultural al que alude Boschín en el capítulo II. Los autores son un sacerdote católico y una monja respectivamente. Le compete al investigador extrapolar filtraciones que el credo de los autores pueda admitir. 


\section{Referencias bibliográficas}

1. Aguerre, A. (2000). Las vidas de Pati. En la toldería tehuelche del río Pinturas y el después. Provincia de Santa Cruz, Argentina. Buenos Aires, Argentina: Universidad de Buenos Aires.

2. Böning, E. (1995). El concepto de pillán entre los Mapuche. Buenos Aires, Argentina: Centro Argentino de Etnología Americana.

3. Fernández Distel, A. (2008). Petrograbados en Inca Cueva (Jujuy) ¿Un arte rupestre soslayado? Versión digital. Recuperado de https://www.academia.edu/31833180/PETROGRABADOS_EN_INCA_CUEVA_J UJUY_UN_ARTE_RUPESTRE_SOSLAYADO

4. Hilger, M. I. (1957). Araucanian child life and its cultural background. Smithsonian Miscellaneous Collections, 133, 3-439.

5. Musters, G. (1964) [1871 edición original]. Vida entre los patagones. Buenos Aires, Argentina: Solar/Hachette.

6. Politis, G. (1998). Arqueología de la infancia: una perspectiva etnoarqueológica. Trabajos de Prehistoria, 55 (2), 5-19. Recuperado de http://tp.revistas.csic.es/index.php/tp/article/ view/300/300

7. Politis, G. (1999). La actividad infantil en la producción del registro arqueológico de cazadores-recolectores. Revista do Museu de Arqueologia e Etnologia, Suplemento 3, 263-283. Recuperado de www.revistas.usp.br/revmaesupl/article/download/113473/111428/ 